\title{
EDUCAÇÃO DO CAMPO: UMA ANÁLISE DA EDUCAÇÃO DO CAMPO E DA FORMAÇÃO DOCENTE, NO MUNICÍPIO DE SÃO FÉLIX DO XINGU-PA, NO PERÍODO DE 2018
}

Viviani de Oliveira Freitas ${ }^{1}$

Resumo: Este artigo tem como objetivo apresentar um estudo a respeito da educação do campo a partir de uma análise da formação docente e a práxis urbanizada no campo. Com esta intenção, diversos autores deram suporte teórico para esta pesquisa, entre eles: Caldart (2008) Arroyo (2004), Brandão (1990), Souza (2006), Zagury (2002), Aranha (2006) e Freire (1996). Verificou-se que o ensino ofertado no meio rural é um ensino urbanizado que não respeita as especificidades desse meio com currículos e planejamentos totalmente voltados para a realidade urbana, porém com um ensino que perde em qualidade e eficácia. Nesse contexto, percebe-se a urgência por ações que favoreça um ensino diferenciado e que respeite as peculiaridades locais. Conclui-se, portanto, que a educação ofertada nestas localidades além de precária não condiz com a realidade do povo que vive e trabalha no campo, além disso, representa um esboço da educação urbana que não contribui para a permanência desses alunos no campo e para uma formação significativa e transformadora.

Palavras - chaves: Educação no Campo. Formação de professores. Práxis docente.

\section{INTRODUÇÃO}

O estudo apresenta uma proposta investigativa em relação à formação e a práxis do professor que atua em áreas rurais, a partir de uma formação voltada para as dinâmicas urbanas.

$\mathrm{Na}$ perspectiva de tornar está pesquisa científica efetivada, este estudo foi desenvolvido na intenção de responder a seguinte problemática: Que efeitos pode haver na formação dos alunos do campo diante do descompasso entre a teoria e a práxis de professores cuja formação é urbanizada?

\footnotetext{
${ }^{1}$ Graduada em Pedagogia pela Universidade Estadual Vale do Acaraú (UVA). Pós-graduada em Educação e Gestão Ambiental pela Faculdade Integrada de Araguatins - FAIARA. Mestre em Ciências da Educação pela Universidade Lusófona. Graduanda no doutorando em Ciências da Educação pela Facultad Interamericana em Ciencias Sociales no qual este estudo é parte do projeto de tese que se encontra em elaboração.
} 
Autores que pesquisaram sobre a educação no campo afirmam que o mesmo apresenta uma importante lição para o processo educacional a partir das dimensões que envolvem a formação humana, ARANHA (2006) diz que para haver uma valorização do professor deve-se começar com a formação do mesmo e, dessa forma, a realidade do campo constitui o lócus desse estudo a qual se baseia a pesquisa desenvolvida.

Nesse propósito, diante dos processos formativos, se observa o professor como um elemento essencial para o ensino e a aprendizagem dos alunos que ao absorverem esses conhecimentos serão reprodutores ou não dessas aprendizagens.

Reproduzir ou reconstruir são processos muitas vezes aprendidos e absorvidos no meio escolar a partir do trabalho desenvolvido por seus mestres.

É uma questão desafiadora, diante da má formação do professor e da realidade em que o mesmo atua, uma vez que em muitos casos a transmissão do conhecimento desse profissional está pautada na realidade urbana em detrimento ao seu lócus de atuação.

Porém, se compreende que é necessária uma mudança nos conceitos relacionados à formação do professor por meio de princípios e valores pautados na formação humana como um todo, respeitando e valorizando os diferentes saberes de forma igualitária com equidade para que de fato haja clareza nas finalidades do ato educativo.

A formação do professor é refletida na sua práxis profissional em seu lócus de trabalho, nesse sentido, uma formação urbanizada corrompe os saberes do campo quando a ênfase desse ensino está voltada para as dinâmicas do meio urbano, sendo necessário que a educação do campo seja potencializada, uma vez que tanto o professor quanto o aluno não foram preparados para absorver a dicotomia do ensino urbano em meio ao campo.

Torna-se relevante pensar na formação docente voltado não só para a sua atuação em ambiente urbano, mas que este professor possa atuar em qualquer realidade em que seu trabalho seja necessário, a partir da superação das condições em que aconteça essa formação.

Por possuir uma dimensão política, o desafio permanece no sentido de uma formação integral e global quando o próprio sistema de ensino é fragmentado.

Desse modo, levar para a práxis os conhecimentos adquiridos na formação inicial requer do professor, principalmente aqueles que atuam no campo, uma reflexão maior, bem como a necessidade de uma formação continuada que coloque em foco a educação do campo para se alcançar e atender a população do campo de forma justa e igualitária no sentido mais amplo da palavra. 


\section{As políticas públicas educacionais para a Educação do Campo}

Para a educação do campo foram criadas algumas políticas públicas educacionais de grande relevância para o desenvolvimento educacional dessa população que se iniciou a partir de um processo de lutas por meio de movimentos sociais, como por exemplo, o $\mathrm{MST}^{2}$ que dá uma dimensão muito mais ampla no cenário nacional do que é veiculado hoje na imprensa e nas mídias sociais.

Esse movimento caracteriza uma luta globalizante na vida social, econômica e intelectual de seus indivíduos no meio coletivo a partir de uma estrutura social em formação que envolve muito mais em sua amplitude do que simplesmente a conquista pela posse da terra, pois nela está intrínseca a conquista também da autonomia, a conquista de direitos, de igualdade e equidade, direito a saúde e a educação de qualidade, de trabalho, de moradia, de lazer, ou seja, direito real a vida no sentido mais amplo da palavra.

E pensando em tudo isso, que esses movimentos têm em sua finalidade a motivação necessária na busca de uma educação de qualidade por meio de políticas públicas que de fato contribua para um fazer pedagógico real, em um sentido mais completo do termo que, segundo Caldart (2004),

\footnotetext{
Pedagogia quer dizer o jeito de conduzir a formação de um ser humano. E quando falamos em matrizes pedagógicas estamos identificando algumas práticas ou vivências fundamentais neste processo de humanização das pessoas, que também chamamos de educação. (CALDART, p.98, 2004).
}

Nessa perspectiva pedagógica, encontramos debates de suma importância a respeito da educação no campo realizado por várias organizações sociais que tem contribuído muito para as escolas do campo através de projetos alternativos como as Casas Familiares Rurais, a Associação de Estudos, Orientação e Assistência Rural (Assesoar), a realização de conferências e debates com a participação de entidades internacionais como a $\mathrm{UNICEF}^{3}$ e a $\mathrm{UNESCO}^{4}$ e entidade nacional como a CNBB que fortaleceu a luta pelo direito e pela valorização do processo educativo no campo.

Também foram criados programas importantes como o Programa Nacional de Educação na Reforma Agrária (PRONERA) e a Política de Educação do Campo

\footnotetext{
${ }^{2}$ MST: Movimento dos Trabalhadores Rurais Sem Terra.

${ }^{3}$ UNICEF: Fundo das Nações Unidas para a Infância.

${ }^{4}$ UNESCO: Organização das Nações Unidas para a Educação, a Ciência e a Cultura.
} 
(PROCAMPO), essas políticas públicas são asseguradas pela LDB 9394/96, no seu artigo 28 que trás em seu teor orientações relevantes para as políticas públicas para a educação no campo, porém são políticas que não são implantadas de forma homogênea em todo o território nacional e que muitas vezes chegam de forma tardia com até 20 anos após muitos projetos de assentamento ter sidos criados em determinadas regiões, como podemos citar os assentamentos em que a pesquisa foi realizada, localizados no município de São Félix do Xingu-Pará.

Portanto, compreende-se, que devido à diversidade histórica, social e regional do Brasil, além de sua grande extensão territorial e geográfica, as peculiaridades da vida no campo apresenta também uma diversidade cultural e econômica muito grande, enquanto que a formação do professor e o sistema educacional continuam sem grandes mudanças, levando em conta uma formação ainda voltada para a realidade urbana, percebe-se que no campo apenas as questões climáticas de cada região são levadas em consideração, porém é relevante considerar a criação de alguns programas que foram destinados à educação no campo, como o PRONERA, que é executado pelo Ministério de Desenvolvimento Agrário (MDE) e pelo Instituto Nacional de colonização e Reforma Agrária (INCRA), o programa é destinado à educação de jovens e adultos e tem por finalidade o fortalecimento educacional no campo a partir de suas especificidades. $\mathrm{O}$ programa contempla em sua finalidade os desejos e anseios do povo do campo, porém, grande parte dessa população ficou à margem dessas políticas públicas.

Outro programa bastante relevante foi o PROJOVEM CAMPO para jovens entre 18 e 29 anos concluir o ensino fundamental com qualificação em agricultura familiar, mas como o PRONERA, apesar de sua relevância, também não contemplou todo o território nacional, sobretudo a região na qual este estudo foi realizado, assim como o PRONACAMPO (Programa Nacional de Educação no Campo).

Apesar de sua importância para o contexto rural, infelizmente também atende apenas alguns regiões do estado, assim como o PROCAMPO que é um programa de apoio à formação superior em Licenciaturas em Educação do Campo destinado aos professores das escolas rurais que lecionam nos anos finais do ensino fundamental e também no ensino médio.

Além desse programa, foram desenvolvidas também algumas ações educacionais para a população do campo como a Escola Ativa que destinava bolsas de estudos para os professores que atuam no campo, infelizmente em algumas localidades foi finalizado 
antes da conclusão do curso por falta de verbas, segundo a secretaria de educação do município na época em que o programa funcionava.

Através do PDDE campo (Programa Dinheiro Direto na Escola) é repassado uma verba em dinheiro para ações de infraestrutura e aquisição de materiais para escolas com até 49 alunos, dessa forma foi possível atender as necessidades algumas escolas. A importância desse programa consiste no fato de que grande parte das escolas com um número igual ou inferior a este mencionado são escolas localizadas em áreas do campo, com salas multisseriadas, que funcionam de forma precária, muitas vezes em áreas de difícil acesso, sem infraestrutura adequada, materiais pedagógicos e didáticos insuficientes, falta de formação do professor, entre outras dificuldades encontradas, que afeta diretamente no trabalho desenvolvido e, sobretudo na qualidade do ensino, porém muitas escolas não tiverem acesso direto a esse recurso, o que comprometeu, evidentemente, o repasse e o destino certo para as melhorias necessárias nas escolas para as quais foi destinado.

Diante disso, a educação no campo continua sendo tratada com políticas compensatórias e sem continuidade, além dos programas destinados para a educação do campo não ser aderida ao mesmo tempo em todo o território e chegando de forma tardia em muitos municípios. Vale ressaltar ainda que são políticas que acontecem em curto período de tempo em algumas localidades e algumas vezes esses programas são encerrados antes mesmo da sua efetivação e, com isso o parâmetro urbano continua sendo utilizado e o do campo utilizando-a com pequenas adaptações que pouco contribui para o desenvolvimento da educação no campo no sentido de promover uma efetiva e significativa mudança no ensino e na aprendizagem.

Lembrando ainda que para o sucesso da educação do campo é necessário que as políticas educacionais, a priori, se voltem para a formação docente, a partir da realidade social, econômica e cultural desse meio conforme a finalidade explicitada, pois é notório que o programa contempla em suas finalidades o desejo e a qualidade necessária para uma educação significativa possível de promover um desenvolvimento sustentável na vida das famílias que residem no campo.

\section{A Educação Do e No Campo numa perspectiva inovadora}

O processo educacional nas áreas rurais tem sido nos últimos anos sinônimo de preocupação e discurso, sobretudo através de movimentos relevantes no país como os 
MST'S, entre outros e, em virtude dessa luta social tem se travado um verdadeiro debate no cenário educacional relacionados à educação no campo e sua efetivação, baseado numa educação que valorize as especificidades socioculturais dessa população. O movimento de Educação no Campo tornou-se uma referência a partir da $1^{a}$ conferência Nacional por uma Educação Básica do Campo em 1998, em Luziânia (GO), todavia em 1889 a concepção de educação rural já existia no Brasil, desde 1930 com certa articulação a respeito da universalização do ensino público.

A partir de 1940, a escolarização no meio rural passou a ter uma nova perspectiva de ensino, as discursões em torno de educação no ou do campo consiste basicamente no fato de definir o tipo de ensino necessário para a população rural e para esse intento é essencial entender a concepção dessa educação definida por diversos autores, entre eles Miguel Arroyo, Bernardo Mançano Fernandes, Mônica Castagna Molina, Roseli Salete Caldart, entre outros para compreender que não basta ter escolas nas áreas rurais se elas não tiverem vinculada a realidade social de seus sujeitos diferenciando-a, portanto da educação rural, uma vez que a Educação do Campo considera seus sujeitos, territórios e a práticas socioculturais de forma diferenciada, ou seja, de acordo com o seu contexto.

A respeito da Educação do Campo, Caldart (2002, p.26) explica que "No: o povo tem direito de ser educado onde vive; Do: o povo tem direito a uma educação pensada desde o seu lugar e com sua participação, vinculada á cultura e ás suas necessidades humanas e sociais", diante dessa visão, a chamada educação rural se torna ínfima diante da dimensão que a Educação do Campo representa por ter nascido das lutas e das experiências pelo direito á uma educação de qualidade a partir dos interesses dos sujeitos do campo, principalmente num período caracterizada pela ausência de políticas educacionais para essa população, pois a Educação Rural, fundamentada numa política voltada para as classes dominantes, privilegia o espaço urbano e ao mesmo tempo em que força a urbanização do rural, além de não respeitar as especificidades regionais bem como o contexto sociocultural, histórico e geográfico dessa população.

A educação rural esta pautada no mundo do trabalho enquanto que a educação do campo leva em conta o contexto sócio - cultural, da população do campo, além disso, a história da educação mostra que o descaso em relação às regiões rurais é muito anterior a esse período e o que há de novo é somente a expressão utilizada para uma definição de territorialidade, a oferta e os interesses embutidos na educação para tais localidades, na prática, continuam os mesmos. 


\section{A Educação no Campo}

No Brasil, existem grandes conflitos pela posse de terras, sobretudo na Região Amazônica, uma vez que em várias regiões do país o processo de reforma agrária tem se dado de forma lenta e bastante desorganizada na maioria das vezes, após diversos conflitos entre os colonos sem terras e funcionários das fazendas, cujas terras pertencem geralmente a União, ou seja, também não pertenciam legalmente aos supostos proprietários das mesmas.

Após a desapropriação da terra dos antigos ocupantes, os colonos são assentados, mas anterior a esta ação muitos colonos residem em acampamentos nas fazendas em conflito ou em torno delas, vivendo em péssimas condições de vida, em barracos de pau a pique, cobertos com palhas ou lona, contam com escolas multisseriadas e na maioria das vezes os professores, pessoas da própria comunidade, sem formação adequada para tal função, suprindo uma necessidade inicial dos alunos relacionada à leitura, escrita e cálculos.

A maior parte das escolas localizadas na zona rural do município de São Félix do Xingu, Estado do Pará, seguem as mesmas diretrizes das escolas urbanas, com pequenas modificações geralmente no calendário escolar, apesar da diferença que existe na formação dos professores, estrutura física das escolas, salas multisseriadas, distorção série/idade, alto índice de repetência nas séries iniciais, evasão escolar, entre outros, coloca as escolas da zona rural em grandes desvantagens no processo educativo em relação à zona urbana.

Essa Tendência hoje é justificada, talvez, pelas relações capitalistas em que o Brasil se encontra, porém para o trabalhador rural não os favorece no sentido de manter a qualidade do ensino e sua permanência no meio rural e como consequência favorece o êxodo rural.

$\mathrm{Na}$ zona rural existe um universo muito grande na área do saber em relação à zona urbana, outra cultura, é nas áreas de assentamento que se percebe a grande diferença na educação, onde a cultura rural é desclassificada e pouco valorizada como se o aluno oriundo de áreas de assentamento pouco necessita para a sua vida diária em termos educacionais.

Não se pode pensar a educação do campo como um bem desnecessário, pois o sucesso dessa educação é o diferencial para o desenvolvimento tanto do indivíduo como também para a comunidade local, além de possibilitar a garantia da permanência dessas famílias nessas áreas. 
A LDB em seu artigo $1^{\circ}$ afirma que "A educação abrange os processos formativos que se desenvolvem na vida familiar, na convivência humana, no trabalho, nas instituições de ensino e pesquisa, nos movimentos sociais e organizações da sociedade civil e nas manifestações culturais" (LDB, 2013, p.13).

Essa educação, garantido pela LDB, muitas vezes tem excluído a população rural por não oferecer meios eficazes que concretize esse direito, ficando, portanto, à margem em relação à oferta e qualidade do ensino uma vez que estas escolas não recebem o tratamento que lhe é devido por parte do sistema educacional brasileiro, de acordo com a lei.

A zona rural é vista, ainda, como um lugar atrasado ao contrário do espaço urbano tido como sinônimo de desenvolvimento social, econômico e cultural, constituindo com isto uma séria preocupação a partir do momento que compromete o processo educacional nessa localidade por não ser dispensada a devida atenção em temos de qualidade e continuidade educacional para essa população.

Conforme Aranha (2006):

É justo pensar que esses bens deveriam estar disponíveis para todos, tanto na fase de reprodução ou de invenção, tanto na de consumo e fruição. No entanto, tal não acontece nas sociedades em que é nítida a separação entre trabalhadores intelectuais e manuais. Nesse caso em que predominam relações de dominação, as pessoas do povo são impedidas de elaborar criticamente a sua própria criação cultural e, consequentemente são excluídas do acesso a esse tipo de bens culturais. E, quando deles se apropriam, tende a prevalecer o consumo da cultura dominante. (ARANHA, 2006, p. 60).

Constatamos que é exatamente isso o que ocorre com a população da zona rural, mais precisamente do município de São Félix do Xingu-PA, onde não há uma educação para o campo e muito menos do campo e sim uma educação totalmente urbanizada e fora do contexto rural que constitui um amplo espaço de ensino e aprendizado.

Arroyo (2004) afirma que:

A Educação do Campo traz, então, uma grande lição e um grande desafio para o pensamento educacional: entender os processos educativos na diversidade de dimensões que os constituem como processos sociais, políticos e culturais; formadores do ser humano e da própria sociedade. (ARROYO, 2004, p.12/13).

Devemos entender que a educação no campo necessita ser vista e garantida a sua população com qualidade e compromisso, pois as instituições responsáveis por essa educação lida com um número significativo de pessoas que direta ou indiretamente interfere no desenvolvimento do país e não deve ser vista como parte minoritária nas políticas de desenvolvimento educacional. 
Um país com tanta desigualdade social constitui um fator negativo para seu índice de desenvolvimento, a educação por sua vez possibilita uma mudança política, social e cultural nesse processo por isso a necessidade de buscar uma educação de qualidade para que o crescimento de nossa sociedade aconteça de fato de forma igualitária, onde se respeite e valorize as especificidades das comunidades rurais.

De acordo com Zagury (2002):

[...]. Por isso é mister tratar de compreender que, se a escola não é ainda hoje aquela ideal, por outro lado, é ainda o único lugar em que nossos filhos encontram pessoas que dedicam suas vidas - assim como nós, pais - a formação das novas gerações. (ZAGURY, 2002, p.14).

A escola nesse contexto constitui uma ferramenta indispensável e primordial para o processo de ensino e aprendizagem bem como para o processo de mudança social, política e econômica, se não ao todo, mas para boa parte da sociedade, Arroyo (2004, p.53) acrescenta que “A educação não levará ao desenvolvimento do campo se não for combinada com reforma agrária e com transformações profundas na política agrícola do país".

É de fundamental importância que se perceba quão necessário é pensar a educação no campo como algo transformador e relevante para o desenvolvimento do país, pois a educação oferecida no campo deve e pode ser tão eficiente para a zona rural quanta aquela que é oferecida na zona urbana, para Arroyo (2004),

\footnotetext{
Um projeto de educação básica do campo tem de incorporar uma visão mais rica do conhecimento e da cultura, uma visão mais digna do campo, o que será possível se situarmos a educação, o conhecimento, a ciência, a tecnologia, a cultura como direitos e as crianças e jovens, os homens e as mulheres do campo como sujeitos desses direitos. (ARROYO, 2004, p.82).
}

No contexto histórico atual se percebe que a educação no campo e os projetos que a acompanham na maioria das vezes não chegam ou demoram muito a serem implantados nos municípios. Em São Félix do Xingu, por exemplo, o Fundo de Fortalecimento da escola (Fundescola) no qual o programa Escola Ativa faz parte, destinado para as escolas multisseriadas, chegou ao município apenas no ano de 2010, mas logo foi extinto sem chegar à conclusão de nenhumas das turmas que iniciou o curso. O Programa de Formação de Professores em exercício (Proformação), que oferece curso de magistério em nível médio, é ofertado no período das férias dos professores, que não tem essa habilitação e estão no exercício da docência nas redes públicas. 
A partir disso, observou-se que a educação nas escolas rurais deixa muito a desejar devido à lentidão com que esses processos ocorrem mesmo na urgência por resultados positivos, tanto professores quanto alunos encontram-se a mercê dos interesses municipais que muitas vezes não tem a educação como prioridade, principalmente quanto se trata de educação no campo, de acordo com Caldart (2008):

\footnotetext{
Os sujeitos que trabalham e vivem do campo e seus processos de formação pelo trabalho, pela produção de cultura, pelas lutas sociais, não têm entrado como parâmetros na construção da teoria pedagógica e muitas vezes são tratados de modo preconceituoso, discriminatório. (CALDART, 2008, p.73).
}

Hoje, no Brasil, o MST e sua busca incessante por reforma agrária tem levantado uma grande discussão pelos direitos humanos, desde a posse como também dos meios de permanência na terra, e isso inclui, sobretudo a questão educacional, pois não se trata mais dos filhos de fazendeiros que só vão ao campo a passeio e sim de filhos dos colonos que necessitam da terra para sobreviver e sua relação com ela é de trabalho, sonhos e necessidades reais. A importância desse movimento e seus anseios têm proporcionando melhorias no campo, conquistando espaços na legislação educacional.

Foram aprovadas, em 2011, as Diretrizes Operacionais para Educação Básica nas Escolas do Campo que define os espaços em que esta educação deve ser oferecida considerando o ser humano com sua produção e suas realizações sociais.

A partir dessas diretrizes Operacionais, pôde-se perceber uma preocupação maior no que diz respeito à Educação do Campo e, em relação a essa relevância, Caldart (2008) esclarece:

\footnotetext{
E há um detalhe muito importante no entendimento da Educação do Campo: o campo não é qualquer particularidade menor. Ela diz respeito a uma boa parte da população do país; se refere a processos produtivos que são à base de sustentação da vida humana, em qualquer país. Não é possível pensar um projeto de país, de nação, sem pensar um projeto de campo, um lugar para seus sujeitos, concretos, para seus processos produtivos, de trabalho, de cultura, de educação. (CALDART, 2008, p.74).
}

A escola é uma das muitas dimensões existentes no que se refere à educação do campo, pois existem outras de igual importância no meio rural, tanto de dimensão escolar quanto naquelas não formais que deve ser valorizada e explorada no sentido de contribuir com o desenvolvimento econômico e social.

A realidade do processo educacional no município de São Félix do Xingu-PA, Região Norte do Brasil, não segue projetos para a educação no campo e a política educacional oferecida não é nem mesmo igual a da zona urbana, pois além de 
descontextualizada, é de má qualidade e não condiz com a realidade dos acampamentos ou mesmo dos assentamentos rurais.

Em várias regiões do Brasil é oferecida formação escolar para os membros dos MST de forma que os mesmos possam de fato atuar de forma direta e transformadora nas escolas localizadas na zona rural, infelizmente estas políticas encontram-se longe da realidade da maior parte dos municípios do Estado do Pará.

O INCRA atuante na região não desenvolve projetos que contribuam efetivamente para o progresso nos assentamentos, tem apenas o papel de demarcar as terras e dividi-las entre os colonos, não existe, portanto uma política de educação voltada para estas áreas com propostas que venham atender as especificidades dessas localidades, com isto estes projetos dificilmente se desenvolvem, pois não oferecem meios eficazes para a permanência dos assentados ou de seus filhos na localidade que por sua vez saem em busca de estudos e empregos na cidade.

Diante dessa realidade, se busca cada vez mais a vida nas cidades como garantia de educação e melhor qualidade de vida, mesmo porque a educação oferecida nas áreas de assentamento não oferece qualidade necessária e não está voltada para o campo, constitui-se de uma educação totalmente urbanizada e voltada para os interesses e a vida na cidade.

A política educacional dos MST muitas vezes não chega ao conhecimento de todos os acampamentos e assentamentos, de forma que os materiais produzidos pelos mesmos não são do conhecimento popular de determinadas regiões.

\section{O professor do campo}

Os professores precisam conhecer mais sobre os movimentos em outras partes do país no intuito de fortalecer uma educação significativa que possibilite o desenvolvimento dessas comunidades de forma dinâmica e transformadora para que esses projetos de assentamento cumpram efetivamente sua função social, respeitando as características próprias dessas localidades e criando alternativas para uma mudança de paradigma na educação de forma que os professores possam estar inteirados do que acontece no movimento, nas políticas educacionais para o campo, sendo sujeitos participantes dos eventos que reúnem as organizações e movimentos sociais.

Sem o envolvimento do professor nas questões pertinentes a educação do campo o processo de mudança consequentemente se dará de forma lenta e pouco eficaz.

Para Nóvoa (2009): 
Nas sociedades contemporâneas, o prestígio de uma profissão mede-se, em grande parte, pela sua visibilidade social. No caso dos professores estamos mesmo perante uma questão decisiva, pois a sobrevivência da profissão depende da qualidade do trabalho interno nas escolas, mas também da sua capacidade de intervenção no espaço público da educação. Se os programas de formação não compreenderem esta nova realidade da profissão docente passarão ao lado de um dos principais desafios deste princípio de século XXI. (NÓVOA, 2009, p.44).

A presença do professor nas áreas de assentamento e o seu trabalho pedagógico pode e deve ir além do espaço escolar, pois seu trabalho nas áreas de assentamento constitui um importante papel na vida sociocultural dos alunos e da comunidade além da escola ser juntamente com a igreja o único patrimônio público da localidade.

Para Brandão (1990):

A ausência absoluta do saber letrado é uma ameaça ao próprio desejo de prosperidade, mais do que uma mera vergonha para um pai de família, com filhos na escola, titular de alguma posse e nome. Todos sabem que a passagem do trabalho grosseiro para o bom emprego, ou para o negócio de proveito, depende sempre da submissão da cultura do trabalho camponês ao poder dos símbolos e códigos da cultura capitalista letrada e urbana. Agora essa passagem depende cada vez mais da adequação da escola rural-embora a menos poderosa, a mais indispensável emissária da cultura letrada. (p.35, 1990).

É imprescindível que as escolas localizadas no meio rural tenham um projeto educacional eficaz, que corresponda de fato às necessidades dessa população de forma que possa contribuir para o progresso e sucesso dos projetos de assentamento, onde os sujeitos ali presentes possam ser agentes de mudanças para que seja possível minimizar a desigualdade social presente em muitos assentamentos rurais.

É necessário que as famílias que residem na zona rural tenham essa visão e busquem melhorias para a educação de seus filhos, não uma educação centrada no que se ensina na cidade, mas que seja contextualizada e voltada para a realidade dessas localidades.

Se a educação é vista nessas comunidades como uma questão cultural, é necessário entender que essa mudança só será possível a partir de interesse das partes envolvidas, ou seja, escola e família, pois ser professor, sobretudo, no sentido de ser um formador de opinião, um agente transformador na sociedade, aquele que é o mediador entre o conhecimento e o saber, supera os desafios de ser apenas o licenciado para ministrar aulas.

Se, na cidade, é um desafio ser professor, quando na maior parte das vezes existe toda uma equipe em busca dos mesmos objetivos, recursos afins, imagine aquela professora ou professor na zona rural, com apenas os alunos e a sala de aula, com 
recursos didáticos e materiais totalmente tradicionais, sala multisseriada, garantia apenas de ensino até o $5^{\circ}$ ano do ensino fundamental, merenda escolar de péssima qualidade e quando é ofertado, além de ter que percorrer vários quilômetros a pé para se chegar à escola e, as localidades com transporte escolar, estes funcionam em péssimas condições de uso.

Para Libâneo (2008):

\begin{abstract}
Maior qualidade do ensino requer investimento prioritário na profissionalização dos professores, implica formação pré-serviço, e formação continuada no trabalho, salários dignos e plano de carreira. A desqualificação profissional do magistério é uma dura realidade que joga por terra qualquer esforço de inovação organizacional, didática e curricular. A revisão dos salários precisa ser acompanhada de programas de aperfeiçoamento profissional, conjugando o reforço nos conteúdos com o desenvolvimento de capacidade de reflexão sobre a prática na prática e novas metodologias de avaliação. (LIBÂNEO, 2008, p. 202).
\end{abstract}

$\mathrm{Na}$ sua maioria, hoje, são professores que sacrificam suas férias para se qualificarem para o trabalho, moram muito distantes da zona urbana e são professores por acaso. Em outras profissões primeiro se qualifica para exercer a profissão, no caso do professor na zona rural é o contrário, primeiro vem à profissão e somente depois sua qualificação, o que constitui um grande desafio devido às peculiaridades do meio rural, porém de acordo com Aranha (2006, p.43) "a revalorização da profissão docente deve começar pelos cuidados com a formação do professor", além disso, Brandão (1990) esclarece que,

Pretender agir como professor sem o ser é uma conduta dificilmente aceita. Todos conhecem as diferenças de saber entre todos. Um professor será essencialmente professor e será tratado de tal modo que todas as condutas para com ele estabeleçam o reconhecimento de tal diferença. (BRANDÃO, 1990, p.155).

Nas escolas da zona rural, o professor ainda é uma figura importante e suas ações tem uma representatividade muito grande nessas localidades, daí é essencial seu papel tanto como professor, mas também de alguém que muito pode contribuir para o progresso sociocultural dessas localidades, seu modo de agir perante a sociedade na qual se encontra pode ajudar e modificar a realidade da população ali envolvida.

Diante dessa perspectiva "espera-se que o profissional da educação seja um sujeito crítico, reflexivo, um intelectual transformador, capaz de compreender o contexto sócio-econômico-político em que se vive" (ARANHA, 2006, p.47), sendo esta uma visão essencial nas comunidades rurais, sobretudo porque, o que o dirigente da igrejinha pensa ou faz, repercute na casa de todos na comunidade assim como as ações do professor, pois conforme Aranha (2006, p.94) “estamos, portanto, aprendendo a cada 
passo, em casa, na igreja, no trabalho, no esporte, com os amigos, com o rádio, com a tevê etc".

Libâneo (2008) afirma que:

[...]. O contexto da vida social, política, econômica e cultural, os espaços de convivência social na família, nas escolas, nas fábricas, na rua e na variedade de organizações e instituições sociais, formam um ambiente que produz efeitos educativos, embora não se constituam mediante atos conscientemente intencionais, não se realizem em instâncias claramente institucionalizadas, nem sejam dirigidas por sujeitos determináveis. (LIBÂNEO, 2008, p. 91).

Apesar de todas essas possibilidades para a produção educativa, o papel do professor ainda é essencial no processo educativo, pois ele representa para a sociedade, sobretudo, a rural, o responsável pela educação formal de seus filhos e é também um indivíduo fundamental para garantir uma educação de qualidade, baseada em princípios éticos e morais.

Para Freire (1996):

O professor que realmente ensina, quer dizer, que trabalha os conteúdos no quadro da rigorosidade do pensar certo, nega, como falsa, a fórmula farisaica do "faça o que mando e não o que eu faço". Quem pensa certo está cansado de saber que as palavras a que falta a corporeidade do exemplo pouco ou quase nada valem. Pensar certo é fazer certo. (FREIRE, 1996, p. 34).

Portanto, o professor representa essa pessoa que deve pensar e fazer certo, uma pessoa que deve servir de exemplo na busca por uma sociedade melhor, pois conforme Brandão (1990) nos evidencia "a passagem da convivência rotineira para a participação social e política realiza-se, na prática e em uma boa medida, sobre o empenho, o saber qualificado e o carisma individual de um agente popular ou erudito de afiliações". (BRANDÃO, 1990, p.164).

No momento que o professor se interesse e se envolva com os problemas dessas comunidades não só sua vida profissional, mas também pessoal terá um novo sentido, pois a partir desse envolvimento, lutará por melhorias no seu âmbito profissional e, consequentemente, estará contribuindo com a comunidade local.

Faz-se necessário entender que os professores da escola rural que se interessa somente com os assuntos da educação não significa que estão preocupadas necessariamente com a escola de um determinado lugar, sua cultura e a maneira como vivem seus habitantes, esta conduta na zona rural é um fator negativo, pois só é possível se sentir parte do processo educativo de uma comunidade quando o professor demonstre interesse tanto pelo seu trabalho como também dos assuntos sociais dessas localidades (BRANDÃO, 1990). 
Um dos maiores problemas da educação na zona rural são as "Escolas de Emergência" como diz Brandão (1990, p.110), esta realidade também esta presente nas escolas de assentamento no Estado do Pará, onde infelizmente, os professores do acaso assim que conseguem obter uma qualificação profissional, buscam melhores condições de trabalho em outras localidades.

Essas escolas além de precárias são organizadas praticamente de improviso, e os professores incialmente são da própria comunidade, muitos deles não possuíam nem mesmo o ensino fundamental completos, daí o porquê de serem considerados professores do acaso, alguns até chegam a conseguir qualificação profissional, mas dificilmente continuam, após a formação, trabalhando nessas localidades.

Outro fator comum da educação nessas áreas é a restrição dispensada ao conhecimento, pois a preocupação inicial da família esta relacionada apenas a leitura e cálculos, não tem uma aspiração maior que isso e consequentemente o saber formal pouco contribuirá para a sua vida futura, tanto em termos pessoais quanto profissionais, diferente da educação almejada pelas famílias de classe média.

Afinal, chegar ao máximo ao $5^{\circ}$ ano do ensino fundamental hoje, significa ter recebido um ensino reduzido, com acesso de má qualidade, a leitura e o cálculo que somente os tira do analfabetismo, tido como característica comum das pessoas oriundas da zona rural, seus conhecimentos são considerados desqualificados perante a sociedade.

O professor que quiser fazer a diferença nessas localidades, prezando a qualidade do ensino em vista do que se espera dele, precisa ir além do ofício, pensar no coletivo, não dá pra ser somente um professor nestas localidades e sim o professor, aquele indivíduo que seja capaz de oferece possibilidades para que aconteça uma transformação entre as pessoas na comunidade.

Contudo, diante da realidade em que se encontram as escolas na zona rural, é preciso realmente ser mais que "professor", necessita de um comprometimento maior, uma parceria indispensável entre escola e família no sentido também de buscar o apoio do poder federal na região de forma que promova um desenvolvimento voltado para as bases naturais e culturais ali presentes, formador de capital humano e social baseado nos conhecimentos dos recursos naturais regionais.

De acordo com Aranha (2006, p.47) é necessário também que,

Esteja atento á intencionalidade de sua ação, questionando continuamente seu saber e agir, articulando o conhecimento sobre educação com a sua práxis educativa, com flexibilidade para inventar caminhas quando a situação 
concreta exige soluções criativas. Enfim, que participe ativamente no propósito da emancipação humana".

Não dá para pensar em educação sem considerar todos esses fatores em prol do sucesso do desenvolvimento educacional, sobretudo nas comunidades rurais, onde o ensino oferecido pouco condiz com a realidade social em questão, pois sabemos que o fator econômico não é o único responsável pelo desenvolvimento, seja ele econômico, social ou cultural.

A riqueza social que envolve a história de luta dos assentados rurais e sua trajetória deve ser vista e entendida como fatores determinantes da luta de uma classe social e cultural, uma luta coletiva e como tal relevante para o processo educacional, onde os indivíduos envolvidos possam adquirir autonomia e responsabilidades na solução dos problemas ali existentes.

A escola pode realmente ser um agente transformador, pois nela encontramos indivíduos de diferentes credos e religiosidade, de diferentes classes sociais e culturais que buscam neste ambiente coletivo muitas vezes os mesmos objetivos.

É claro que, se não na sociedade toda, mas ao menos em uma parte terá feito a diferença, o que reforça a necessidade de profissionais que sejam sujeitos transformadores da realidade que estão inseridos partindo da compreensão de que a escola é mais que um espaço de instrução, pois trás em si uma gama de pressupostos "que representam as relações de poder vigentes e convicções pessoais nem sempre explicitadas" (ARANHA, 2006, p. 47).

Não devemos evidentemente, esperar que a escola sozinha assuma tal responsabilidade, daí a importância da sintonia entre escola e família nesse processo, de forma que haja uma integração real entre os setores dessas comunidades, principalmente na sociedade atual, cujo tal ofício perdeu se não o valor, mas o respeito com certeza, pois ser professor, hoje, é muitas vezes falta de opções ou formação, principalmente no interior do país, onde primeiro qualquer um exerce esta profissão de acordo com a necessidade e com o decorrer do tempo a abandona ou se qualifica, na maioria das vezes precariamente.

Algumas escolas em área de assentamento são organizadas na necessidade vigente do momento, sem planejamento ou mão-de-obra qualificada inicialmente, nesses projetos de reforma agrária no sudeste da Região Norte, é de responsabilidade do INCRA que em algumas regiões não apresentam nada além da demarcação e 
distribuição de terras, sendo que anterior a esta ação por parte desse órgão, as terras são invadidas por trabalhadores Sem Terras, após anos de incertezas e conflitos com fazendeiros, não havendo, portanto, um planejamento para o desenvolvimento e permanência das famílias assentadas em muitas das localidades de assentamento.

Geralmente a educação é vista por grande parte da sociedade como um meio de ascensão social e a partir dessa visão a escola adquire um papel fundamental para proporcionar essa mudança, por outro lado a mudança nos serviços dessa educação ocorre em virtude dos interesses e necessidades de alguns poucos em relação das necessidades da grande maioria.

É preciso que a família perceba que para a escola do campo ter êxito no processo de ensino-aprendizagem não basta somente ela fazer parte desse processo de ensinoaprendizagem, é necessário ter consciência do seu papel e perceba a importância de sua contribuição nesse processo.

A escola necessita de profissionais compromissados com a tarefa de ensinar, de pessoas que pensem no coletivo e, sobretudo, no trabalho e no desenvolvimento ao menos da comunidade em que se encontra inseridos em prol de uma educação mais justa, de oportunidades iguais e de direitos respeitados afinal "imaginar que a escola seja um local, apolítico, em que são transmitidos conhecimentos objetivos e apartados do mundo das injustiças sociais, é manter uma postura conservadora. Perigosamente conservadora, por contribuir para a manutenção do "status quo"” (ARANHA, 2006, 47).

A educação oferecida na zona rural além de fugir, na sua totalidade, da realidade sociocultural dos alunos, não oferece nenhuma expectativa de melhorias ou continuidade dessa educação no sentido de buscar uma melhor qualidade de vida e permanência nessas localidades.

O professor que se disponibiliza a trabalhar nessas localidades se não tiver consciência de seu papel, pouco ou nada terá a oferecer a esses alunos.

Mesmo nos projetos voltados para a educação de jovens e adultos nessas localidades, falta, sobretudo, a coragem necessária, conforme Freire contra uma "Educação Bancária", de uma educação voltada para realidade, de um engajamento entre escola e família para realmente ter um papel relevante na localidade onde atua.

Acredito que, esta educação para jovens e adultos só tem servido realmente para obtenção de um certificado que comprove certa escolaridade para que este indivíduo possa ser inserido no mercado de trabalho. Muitas vezes consequência de um ensino de 
má qualidade, falta de projetos educacionais eficazes e de professores competentes ou pouco conscientes de sua responsabilidade e de seu papel na sociedade.

A sociedade, de modo geral, tem que buscar esse tipo de educação e não aceitar que uma minoria possa ser dono de uma formação integral e não se der por satisfeitos com as migalhas que lhe são oferecidos, é necessário ter objetivos definidos, vontade e consciência, acima de tudo, que a educação universal que a Constituição Federal garante é um direito de todos, mas a grande maioria para ter esse direito precisa ir além das suas possibilidades sociais e econômicas para que não fiquem a mercê desse sistema capitalista e excludente, além de um processo de globalização que acentua cada vez mais as diferenças entre as classes sociais.

\section{Considerações Finais}

O estudo está em fase de elaboração, fazendo parte do projeto de tese de doutorado, o qual se faz uma análise a respeito da formação do professor bem como da dicotomia entre o ensino ofertado na zona urbano e o ensino no campo, no município de São Félix do Xingu, Estado do Pará, pois ainda constitui uma preocupação por não possuir nenhum projeto educativo real, que dê uma atenção significativa aos professores que atuam e residem no campo, além disso, o município é muito grande possuindo longas distâncias até a sede do município, sendo uma região ainda de difícil acesso entre o campo e a cidade.

Percebemos que para a comunidade campesina a escola é vista como o principal meio de formação e ascensão no plano sociocultural e econômico. Existe, portanto, uma expectativa e um interesse de grande valor social nos projetos de assentamento pesquisados.

A escola tem, muitas vezes, desempenhada um duplo papel tanto na formação do caráter do indivíduo quanto no ensino-aprendizagem dos mesmos, e isto acarreta danos irreparáveis no desenvolvimento integral da criança, pois a família não pode deixar de fazer valer seu papel uma vez que nada a substitui.

Pesquisar sobre e a Educação do Campo, sobretudo sobre a formação do professor nos permitiu fazer uma análise a respeito do descompasso entre a formação docente urbanizada e a práxis docente no meio rural, no município de São Félix do Xingu-Pará, atentos aos processos de mudanças em todos os setores sociais que tem 
ocorridos num ritmo tanto acelerado quanto desorganizado, afetando diretamente as comunidades menos preparadas e muitas vezes isoladas desse contexto.

$\mathrm{O}$ interesse pelo objeto de pesquisa partiu da experiência como aluna e posteriormente professora no campo.

A pesquisa realizada possibilitou verificar que tanto a formação docente quanto o ensino ofertado no campo não condiz com a realidade local que, além de ser descontextualizado, discrimina e marginaliza a população do campo, nesse contexto, tanto a escola quanto a família precisam estar juntas na luta por uma educação de qualidade que respeite valorize suas especificidades.

Acreditamos que a parceria entre escola e família é fundamental para uma aprendizagem significativa e transformadora, assim com o objetivo de compreender as características da educação no campo em áreas de reforma agrária, principalmente a formação do professor.

Apesar do resultado positivo, verificamos que a família é bastante acomodada em relação à escola no que diz respeito às questões de funcionamento, infraestrutura, materiais utilizados, entre outros, pois o que se percebe é certa harmonia entre a família e o professor e nos poucos eventos ali realizados.

Com esta perspectiva, acredito ainda que apesar das peculiaridades e contradições existes no meio educacional, como profissionais podemos ao menos minimizar os problemas encontrados na escola e diminuir os danos existentes no ensino e na aprendizagem, a convicção de que a mudança além de necessária também é possível.

Destacamos ainda que esse trabalho não é conclusivo, por compreender a necessidade de mais estudos a respeito da temática abordada, pois a educação do campo bem como escola e família abrange diferentes realidades e dimensões sociais relevantes e essenciais para a população do campo e também para a realização de estudos posteriores.

\section{Referências}

ARANHA, Maria Lucia de Arruda. Filosofia da Educação. 3. Ed. rev. e ampl. São Paulo: Moderna, 2006.

ARROYO, Miguel Gonzalez. CALDART, Roseli Salete. CASTAGNA, Mônica Molina (organizadores). Por uma educação no campo. Petrópolis, RJ: Vozes, 2004. 
BRANDÃO, Carlos Rodrigues. O trabalho do saber: cultura camponesa e escola rural. São Paulo: FTD, 1990.

BRASIL, Constituição da República Federal do Brasil. 22. Ed. São Paulo: EDIPRO, 2013.

LDB: Lei de Diretrizes e Bases da Educação. Antônio de Paulo (ed).

Petrópolis, RJ: De Petrus et alii, 2013.

CALDART, Roseli Salete. A escola do campo em movimento. IN: ARROYO, Miguel Gonzales; CALDART, Roseli Salete e MOLINA, Mônica Castagna (orgs). Por uma educação do campo. Petrópolis: Vozes, 2004.

Sobre educação do campo. IN: Fernandes, Bernardo Maçano [et al]. Santos, Clarici Aparecida dos. (org). Educação do Campo: campo-políticas públicas educação. Brasília: INCRA, MDA. NEAD Especial 10, p. 67-86, 2008.

Por uma Educação do Campo. In: Kolling, Edgar José et all (org). Educação do Campo: Identidade e Políticas Públicas. Coleção Por uma educação do campo. ${ }^{\circ}$ 04. Brasília: DF. Articulação Nacional Por Uma Educação do Campo, 2002.

DI SANTO, Joana Maria. Família e Escola: uma relação de ajuda. 2007. Disponível em: www.centrorefeducacional.com.br. Acessado em 30.01.2007.

FERREIRA, Aurélio Buarque de Holanda. Miniaurélio Século XXI Escolar: O minidicionário da língua portuguesa. 4. ed. rev. ampliada. Rio de Janeiro: Nova Fronteira, 2001.

FREIRE, Paulo. Pedagogia da Autonomia: saberes necessários à prática educativa. São Paulo: Paz e Terra, 1996.

LIBÂNEO, José Carlos. José Carlos. Pedagogia e Pedagogos, para quê?/ 10. ed. São Paulo, Cortez, 2008 .

NÓVOA, Antônio. Professor: Imagens do Futuro Presente. Lisboa: Educa, 2009.

ROMANELLI, Otaíza de Oliveira. História da Educação no Brasil: (1930/1973). 36. ed. Petrópolis, RJ. Vozes, 2010.

SOUZA, Maria Antonia de. Educação do Campo: propostas e práticas pedagógicas do MST. Petrópolis, RJ: Vozes, 2006.

ZAGURY, Tânia. Escola sem conflito: parceria com os pais. - Rio de Janeiro: Record, 2002. 
